\title{
Implicit memory for visual objects and the structural description system
}

\author{
DANIEL L. SCHACTER \\ University of Arizona, Tucson, Arizona \\ LYNN A. COOPER \\ Columbia University, New York, New York \\ and \\ SUZANNE M. DELANEY \\ University of Arizona, Tucson, Arizona
}

\begin{abstract}
Several experiments are described in which priming or implicit memory for visual objects was investigated. In one set of studies, subjects were shown line drawings of unfamiliar objects that were either structurally possible or structurally impossible. Implicit memory was assessed with a possible/impossible object-decision task, and explicit memory was assessed with a recognition task. The results revealed significant priming for possible objects following study tasks that required encoding of three-dimensional object structure; semantic/elaborative study processing enhanced explicit but not implicit memory. No priming of impossible objects was found. An experiment using familiar objects also revealed that priming, but not explicit memory, was independent of semantic/elaborative study processing. It is suggested that priming of visual objects depends on a presemantic system that is dedicated to the representation of object form and structure and can function independently of episodic memory.
\end{abstract}

Research on priming and implicit memory has focused heavily on verbal materials such as words, paired associates, and the like. There has been a good deal less research on implicit memory for nonverbal materials, and with the exception of work by several investigators (e.g., Bentin \& Moscovitch, 1988; Gabrieli, Keane, Milberg, \& Corkin, in press; Kroll \& Potter, 1984; Musen \& Treisman, 1990), this research has focused exclusively on priming of pictures of familiar objects (for a review, see Schacter, Delaney, \& Merikle, in press). In this paper, we describe a series of recent studies in which we have examined priming for both novel and familiar visual objects. To preview our main findings, we documented priming of both types of objects, showed that such priming depends on processing of structural but not semantic information, and dissociated implicit and explicit memory for target objects. We will argue that priming of visual objects depends on what we and others have referred to as the structural description system (Riddoch \& Humphreys, 1987; Schacter, in press; Schacter, Cooper, \& Delaney, 1990)-a presemantic system that is dedicated to the representation of the form and structure, but not the functions or other associative properties, of visual objects.

This research was supported by a grant from the Air Force Office of Scientific Research. We thank Elizabeth Merikle, Mary Peterson, and Mindy Tharan for their contributions to the research described in this article. Correspondence should be addressed to Daniel L. Schacter, Department of Psychology, University of Arizona, Tucson, AZ 85721.

\section{Object-Decision Priming: Initial Studies}

The first series of experiments to be considered was directed to the question of whether implicit memory could be observed for novel three-dimensional objects that have no preexisting representation in memory. In an initial experiment and several others that will be described, subjects studied 20 line drawings that represented unfamiliar and rather unusual three-dimensional constructions such as those displayed in Figure 1. Two encoding conditions were used. One group of subjects was induced to encode information about the global structure of each object by deciding whether the object faced primarily to the left or to the right. A second group of subjects was induced to encode information about the local features of each object by deciding whether it had more horizontal or vertical lines.

After completing these encoding tasks, half of the subjects in each group were given an explicit memory test-a standard yes/no recognition test in which they were shown studied and nonstudied drawings and indicated whether or not they remembered seeing them previously. The other half of the subjects were given an object-decision test. Although the subjects were not informed of it at the time of encoding, half of the line drawings that they studied were structurally possible objects-their surfaces and edges were connected in such a way that they could potentially exist in three-dimensional space. The other half were structurally impossible objects-they contained surface and edge violations that would prohibit them from actually existing in the three-dimensional world. We gave the 

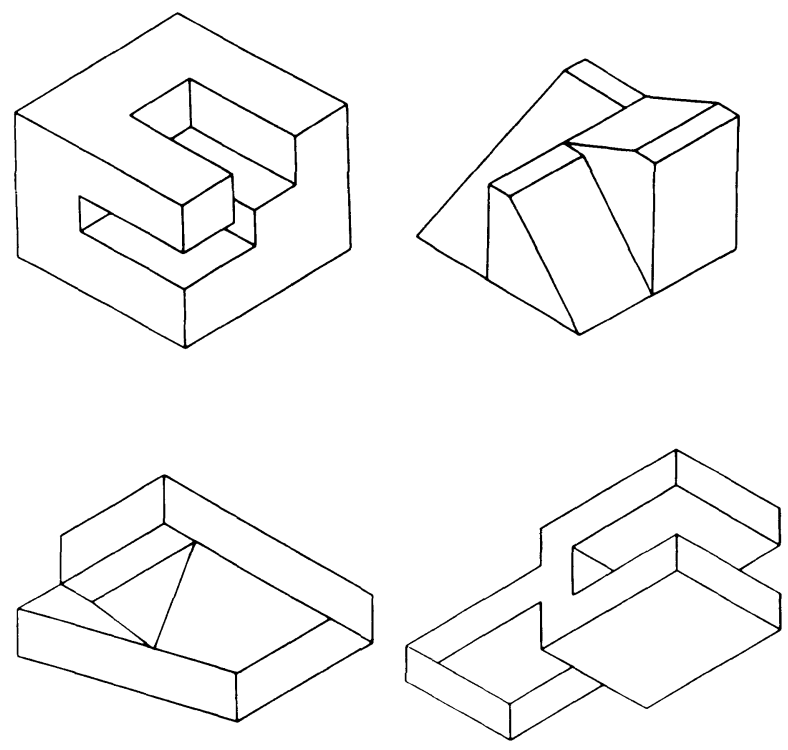

Figure 1. Examples of novel objects used in the experiments by Schacter, Cooper, and Delaney (1990). The two objects in the upper row are structurally possible; the two objects in the lower row are structurally impossible. See text for further explanation.

subjects 100 -msec exposures to drawings of studied and nonstudied possible and impossible objects; their task was to decide whether each object was possible or impossible. The object-decision task can be thought of as an implicit memory test in the sense that it does not make explicit reference to, or require conscious recollection of, any specific previous encounter with a presented object. If, therefore, subjects are more accurate in making object decisions about studied than about nonstudied objects, there would be some evidence of implicit memory for these unfamiliar, three-dimensional objects. More specifically, we reasoned that performing the object-decision test requires analysis of the global structure of the object; subjects must gain access to information about global structural relations in order to decide whether an object is possible or impossible. Consistent with such notions as transfer-appropriate processing (e.g., Roediger, Weldon, \& Challis, 1989), it follows that prior encoding of information about global object structure-but not local object features-should produce priming or implicit memory on a subsequent object-decision task.

The results of our first experiment were consistent with this hypothesis. Consider first the results for the structurally possible objects. We examined object-decision performance as a function of the left/right or horizontal/vertical encoding task and as a function of whether or not an item had been studied. In addition, the group of subjects who were given the recognition test were also given an object-decision test after it. Thus, we could examine object-decision performance as a function of whether it was given as the first or the second test.

The data presented in Table 1 are collapsed across the two object-decision tests, because performance did not differ as a function of whether object decision was the first or second test (see Schacter, Cooper, \& Delaney, 1990). Table 1 indicates that object-decision performance was significantly more accurate for studied than for nonstudied drawings following the left/right study task. However, there was no significant difference between studied and nonstudied objects following the horizontal/vertical study task. Thus, we found that implicit memory for unfamiliar objects depends on the encoding of and access to a global, three-dimensional structural description of an object. In addition, the fact that the appearance of studied and nonstudied objects on the recognition test did not facilitate subsequent object-decision performance suggests that deciding whether an object is old or new, at least under these test conditions, does not involve the sort of structural encoding that is needed to produce priming on an object-decision test. Table 1 also indicates that the structurally impossible objects showed no priming under any experimental condition: objectdecision performance for studied and nonstudied impossible objects was virtually identical.

Whereas priming of novel, structurally possible objects was observed only following global structural encoding, the recognition data indicated that explicit memory did not differ significantly following the left/right and horizontal/vertical study tasks (Schacter, Cooper, \& Delaney, 1990). In addition, recognition of impossible objects, although lower than recognition for possible objects, was reasonably good, in contrast to the absence of priming for impossible objects. Finally, a contingency analysis of the relation between recognition and priming revealed stochastic independence between the two tasks.

Further evidence for implicit/explicit dissociation was provided by a second experiment, in which one group of subjects engaged in an elaborative encoding task that required them to generate a real-world object that each drawing reminded them of most (Schacter, Cooper, \& Delaney, 1990, Experiment 2). We hypothesized that such a task would require the subjects to achieve a meaningful interpretation of the object by relating it to preexisting semantic knowledge. On the basis of many previous demonstrations that explicit memory is enhanced by semantic elaboration, we reasoned that this elaborative study task should enhance recognition performance relative to the left/right encoding task used in the first ex-

Table 1

Object-Decision Performance as a Function of Encoding Task

\begin{tabular}{lcc}
\hline & \multicolumn{2}{c}{ Encoding Task } \\
\cline { 2 - 3 } Item Type & Left/Right & Horizontal/Vertical \\
\hline \multicolumn{3}{c}{ Possible Objects } \\
Studied & .81 & .67 \\
Nonstudied & .67 & .64 \\
\multicolumn{3}{c}{} \\
Studied & Impossible Objects \\
Nonstudied & .67 & .60 \\
\hline
\end{tabular}

Note-Data are adapted from Schacter, Cooper, and Delaney (1990). 
Table 2

Object-Decision and Recognition Performance as a Function of Encoding Task

Type of Test/Encoding Task

\begin{tabular}{lccccc}
\cline { 2 - 3 } Item Type & \multicolumn{2}{c}{ Object Decision } & & \multicolumn{2}{c}{ Recognition } \\
\cline { 2 - 3 } \cline { 5 - 6 } & Left/Right & Elaborative & & Left/Right & Elaborative \\
\hline Studied & .78 & .76 & & .69 & .88 \\
Nonstudied & .66 & .73 & & .21 & .19 \\
\hline
\end{tabular}

Note-Data are presented for structurally possible objects only. For object decision, the proportion of correct responses to studied and nonstudied objects is shown; for recognition, the proportion of "yes" responses to studied objects (hits) and "yes"' responses to nonstudied objects (false alarms) is shown. Data are adapted from Schacter, Cooper, and Delaney (1990).

periment. However, since the elaborative task does not involve specific structural encoding of the objects, it should not lead to more accurate object-decision performance than did the left/right task.

The results were consistent with this expectation, and in fact revealed a rather dramatic dissociation between recognition and object-decision performance (Table 2). We will consider only the structurally possible objects, since the impossible objects once again showed no priming. On the recognition test, elaborative encoding led to much higher levels of explicit memory than did left/right encoding. A contrasting pattern of results was observed on the object-decision task: no priming was observed following the elaborative task, whereas significant priming was observed following the left/right task, in replication of Experiment 1. This dissociation is impressive because there have been few studies in which an experimental manipulation that improves explicit memory also impairs implicit memory. However, the fact that we observed no priming in the elaborative condition was rather surprising. In a follow-up experiment, we were able to show that this lack of priming was attributable to the fact that subjects frequently generated two-dimensional elaborations of the target objects (e.g., indicating that a side of the object reminded them of a letter, a cross, etc.). When we asked them to generate three-dimensional elaborations, significant priming was observed, although it was no greater than that observed in the left/right condition (Schacter, Cooper, \& Delaney, 1990, Experiment 3).

In each of the foregoing experiments, object-decision performance was assessed after a retention interval of several minutes. To determine whether the priming effect observed under these conditions persists across longer delays, we have more recently assessed object-decision and recognition performance after retention intervals of 1 or $24 \mathrm{~h}$. All 72 subjects who participated in the experiment performed the left/right encoding task described in the previous experiments, and the same set of objects described by Schacter, Cooper, and Delaney (1990) was used. Half of the subjects were tested after a 1-h delay, and half were tested after a 24-h delay; at each delay, 18 subjects were given an object-decision task alone and 18 were given the object-decision task following a yes/no recognition test.
Object-decision data for the two delays are presented in Table 3. Consider first the data for the structurally possible objects. At the 1-h delay, significant priming of possible objects was observed, and the difference between studied and nonstudied items was about the same whether the object-decision test was given alone or following a recognition test. Although there was a trend for overall higher performance when the object-decision test was given following the recognition test, statistical analysis revealed only a main effect of priming (i.e., studied vs. nonstudied objects; $p<.001$ ); there was a nonsignificant main effect of test order and no interaction between test order and priming. At the 24-h delay, there was some evidence of priming when the object-decision test was given alone, but there was no difference between the two when the object-decision test was given second (Table 3). This latter finding may be attributable to a test-priming effect for nonstudied objects. However, statistical analysis failed to show significant main effects of priming or test order and also showed a nonsignificant interaction between these two variables. Finally, no priming of impossible objects was found at either delay. On the recognition test, performance declined from 1 to $24 \mathrm{~h}$ for both possible and impossible objects: corrected recognition (hits - false alarms) scores for possible objects were .56 at the 1-h delay and .38 at the 24-h delay; the corresponding proportions for impossible objects were .46 and .24 .

The foregoing data indicate that priming effects for structurally possible objects are robust at a 1-h delay; the magnitude of priming in this condition is comparable to that observed after a delay of several minutes. Although there was a trend for priming at the 24-h delay when the object-decision test was given alone, these results are equivocal at best and require further empirical investigation.

\section{Is There Priming with Structurally Impossible Objects?}

As noted above, an intriguing finding from the initial set of experiments concerns the failure to observe prim-

Table 3

Object-Decision Performance as a Function of Retention Interval and Test Order

\begin{tabular}{|c|c|c|c|c|c|c|}
\hline \multirow[b]{3}{*}{ Item Type } & \multicolumn{6}{|c|}{ Retention Interval/Test Order } \\
\hline & \multicolumn{3}{|c|}{1 Hour } & \multicolumn{3}{|c|}{24 Hours } \\
\hline & First & Second & $M$ & First & Second & $M$ \\
\hline \multicolumn{7}{|c|}{ Possible Objects } \\
\hline $\begin{array}{l}\text { Studied } \\
\text { Nonstudied } \\
\qquad M\end{array}$ & $\begin{array}{l}.80 \\
.68 \\
.74\end{array}$ & $\begin{array}{l}.87 \\
.77 \\
.82\end{array}$ & $\begin{array}{l}.84 \\
.73\end{array}$ & $\begin{array}{l}.76 \\
.68 \\
.72\end{array}$ & $\begin{array}{l}.77 \\
.76 \\
.77\end{array}$ & $\begin{array}{l}.77 \\
.72\end{array}$ \\
\hline \multicolumn{7}{|c|}{ Impossible Objects } \\
\hline $\begin{array}{l}\text { Studied } \\
\text { Nonstudied } \\
\qquad M\end{array}$ & $\begin{array}{l}.60 \\
.62 \\
.61\end{array}$ & $\begin{array}{l}.70 \\
.66 \\
.68\end{array}$ & $\begin{array}{l}.65 \\
.64\end{array}$ & $\begin{array}{l}.71 \\
.74 \\
.73\end{array}$ & $\begin{array}{l}.64 \\
.62 \\
.63\end{array}$ & $\begin{array}{l}.68 \\
.68 \\
.68\end{array}$ \\
\hline
\end{tabular}

Note-Test order refers to whether object decision was the first test given at the end of the retention interval, or the second test given, after a yes/no recognition test. 
ing of impossible objects despite reasonably good explicit memory for these objects. Schacter, Cooper, and Delaney (1990) speculated that this failure may reflect a limitation of the structural description system's computational capacities: it may be difficult to form a global representation of the structure of an impossible object. However, other interpretations of the phenomenon are possible. For example, in order to select the set of possible and impossible objects used in the foregoing experiments, we initially presented the objects to a separate group of subjects for an unlimited amount of time and asked for a possible/impossible judgment. These subjects classified $97 \%$ of the possible objects correctly under these unlimited viewing conditions, but they classified only $87 \%$ of the impossible objects correctly. Failure to observe priming of impossible objects might thus be partially attributable to the fact that there was less agreement about the impossible objects than about the possible objects. In addition, our instructions on the object-decision test emphasized detection of possible objects; the subjects were instructed to push one response key if an object "could be a possible object" and another if it "could not be a possible object." An impossible response was thus effectively a negative response, which might have worked against observing priming of the impossible objects. Finally, explicit memory for impossible objects in our initial experiments was consistently lower than explicit memory for possible objects. Thus, failure to observe priming of impossible objects may be attributable to a generally "weak" memory representation.

To evaluate these issues, and to explore further the nature of priming for possible objects, we have recently undertaken a series of experiments containing several procedural changes (Schacter, Cooper, Delaney, Peterson, \& Tharan, 1990). First, we calibrated a new set of target objects in which there was $99 \%$ agreement for both the possible and the impossible objects. We also altered the task instructions so that an "impossible" response was no longer a negative response, and added several more examples of impossible objects to the instructional phase of the test to ensure that the subjects fully understood what made an object impossible.

We then examined priming following the left/right structural encoding task used in the previous experiments under two conditions of repetition: the study list of 20 possible and impossible objects was presented either once or four times, with the subjects thus making four left/right judgments for each object in the latter condition. Inclusion of the four-repetition condition served two purposes. First, if priming of impossible objects is not observed even after four left/right judgments, when explicit memory is likely to be quite good, then it would be difficult to argue that a lack of priming for impossible objects is simply attributable to a weak memory representation. Second, the repetition manipulation also allowed us to determine whether the magnitude of the priming effect for possible objects can be increased. The number of repetitions was a between-subjects factor; the design of the experiment was otherwise identical to the previous ones.
Consider first the results from the recognition test. Not surprisingly, recognition memory (as assessed by a hits - false alarms measure) was significantly $(p<.05)$ higher following four exposures than following one exposure for both possible objects (.70 vs. .41) and impossible objects (.62 vs. .33). A rather different pattern of results was observed for the object-decision data for possible objects. In the one-exposure condition, a priming effect similar to that observed in the previous experiments was found: object-decision accuracy was higher for studied (.74) than for nonstudied (.62) possible objects. In the four-exposure condition, object-decision performance showed a virtually identical pattern (.71 for studied objects and .58 for nonstudied objects). Statistical analysis revealed a main effect of priming $(p<.01)$ and a nonsignificant interaction between priming and number of repetitions. Thus, repetition had a large effect on recognition performance and no effect on the magnitude of priming, thereby providing yet another dissociation between implicit and explicit memory for novel objects.

Turning to the data on the impossible objects, objectdecision performance was indistinguishable for studied and nonstudied objects following both one study-list exposure (.67 vs. .67) and four study-list exposures (.66 vs. .65). Indeed, a lack of priming for impossible objects in the four-exposure condition was observed even though recognition of impossible objects in this condition was a good deal higher than recognition of possible objects following a single exposure, where significant priming was observed. Thus, the absence of priming for impossible objects cannot be ascribed to some sort of generally weak memory representation of these objects. These results also provide evidence against the idea that a failure to observe priming of impossible objects is attributable to low agreement about the impossible objects or to test instructions that make the "impossible" response a negative response.

The foregoing results suggest that it may indeed be impossible to observe priming of impossible objects, but further research is needed before such a conclusion is warranted. For example, in the studies discussed thus far, no attempt was made to equate the size of possible and impossible objects. In recent pilot work we have investigated priming with size-equated objects. Although we do not yet know whether this experiment will show priming for impossible objects, it underscores the need for caution in interpreting the data on impossible objects.

\section{Priming of Familiar Visual Objects}

Our studies with the object-decision task indicate that priming of novel objects is dependent on encoding structural, but not semantic, information about target items. Similar conclusions have been suggested by a recent experiment on priming of familiar visual objects (Schacter \& Merikle, 1990). A sizable body of literature exists concerning priming of familiar objects, but little attention has been paid to the roles of structural and semantic encoding processes (see Schacter et al., in press, for a discussion). To investigate this issue, we used a set of materials that was compiled from a variety of sources by E. P. Merikle 
and M. A. Peterson, which consisted of line drawings of familiar objects and perceptually degraded fragments of these objects. Merikle and Peterson selected fragments in which minima of curvature were preserved, thereby providing useful perceptual information about each object.

In the Schacter and Merikle (1990) experiment, subjects were initially exposed to a series of line drawings of each object for $5 \mathrm{sec}$; they performed a semantic orienting task for half of the drawings and a structural orienting task for the other half. In the semantic orienting task, the subjects generated functions for each object; in the structural task, the subjects counted the number of vertices in each object. To assess priming, perceptual fragments of studied objects were presented together with an equal number of fragments of nonstudied objects. In previous studies of picture fragment completion, subjects have generally been asked to identify each object (e.g., Snodgrass, 1989; Warrington \& Weiskrantz, 1968; Weldon \& Roediger, 1987). As Schacter et al. (in press) have pointed out, however, such instructions allow and may even encourage subjects to use explicit memory strategies to aid object identification, as indicated by the fact that strong dissociations between priming and explicit memory have been difficult to obtain using the traditional picture fragment-completion paradigm. To circumvent this problem, Schacter and Merikle modified the fragmentcompletion instructions so that the subjects were told to respond to each fragment with the first object that came to mind. The subjects were further instructed that there was no right or wrong response on this task, and that any object would do as a completion response (see Butters, Heindel, \& Salmon, 1990, for a similar procedure). To further discourage the use of explicit strategies, fragments were presented for $500 \mathrm{msec}$ and the subjects were instructed to respond as quickly as possible. A separate group of subjects was given an explicit memory test in which the same fragments were presented as cues, but these subjects were instructed to think back to the study list and indicate which studied object was represented by the test fragment.

The results revealed significant priming $(p<.01)$ on the fragment-completion task and, more importantly, almost identical levels of priming following the semantic and structural study tasks: baseline probability of responding with the correct object for nonstudied items was .22 , compared to .45 for objects that had been studied in the semantic task and .46 for objects that had been studied in the structural task. In contrast, explicit memory was significantly $(p<.05)$ higher in the semantic condition (.83) than in the structural condition (.69). The fact that performance was higher in the semantic than in the structural condition with recall instructions, but not with completion instructions, indicates that the priming effect was not based on explicit memory. The fact that priming was just as large following the vertex-counting task as following the function-generation task indicates that nonsemantic, structural processing is sufficient to produce robust priming of familiar visual objects.

\section{Priming of Visual Objects: Theoretical Implications}

Our experiments have delineated two features of priming, which were observed with novel objects on the objectdecision task and familiar objects on the fragmentcompletion task, that are of special theoretical relevance. First, the phenomenon is presemantic, in the sense that priming does not require any semantic or elaborative processing of target objects. Second, encoding of information about object structure appears to be a sufficient and perhaps necessary condition for priming. In these respects, object priming is similar to more extensively studied word-priming effects on data-driven implicit tests such as word identification and word completion, where priming is typically independent of semantic study processing and depends critically on encoding of appropriate perceptual and structural information about words (Roediger et al., 1989; Schacter, in press).

We have found it useful to conceptualize these kinds of presemantic, perceptually dependent priming effects in the context of neuropsychological studies concerning disorders of reading and object processing. This line of research has provided strong evidence for the existence of presemantic systems that are dedicated to the representation and retrieval of information about the form and structure, but not the meaning, of words and objects. Specifically, we have argued that a presemantic perceptual representation system (PRS), composed of a number of related subsystems, plays a major role in priming on datadriven implicit tests (see Schacter, in press; Schacter et al., 1990; Tulving \& Schacter, 1990). In the verbal domain, various kinds of neuropsychological and neuroimaging evidence have provided converging support for the existence of a visual word-form system (e.g., Peterson, Fox, Posner, \& Raichle, 1988; Schwartz, Marin, \& Saffran, 1980). We have argued that this subsystem of PRS is critically involved in word-priming effects on such implicit tests as word identification and completion (Schacter, in press; Schacter, Rapscak, Rubens, Tharan, \& Laguna, 1990).

More directly relevant to the present experiments is the neuropsychological research by Warrington $(1975,1982)$ and Riddoch and Humphreys (1987) concerning agnosic patients with object-recognition disorders. These investigators have studied patients who are seriously impaired in gaining access to semantic or functional information about objects. Such patients cannot name common objects, are unable to answer questions about what such objects are used for, and fail to demonstrate knowledge of where familiar objects are typically found. Yet the same patients perform reasonably well on tests that require processing of object structure. These kinds of dissociations have led to the postulation of a presemantic structural description system for objects (Riddoch \& Humphreys, 1987; Warrington, 1982), which we view as a subsystem of PRS. We believe that object priming in our experiments is driven largely by this system - that is, initial study of an object creates a structural description of it, which is then 
accessed implicitly during performance of an objectdecision or object-completion test, thereby producing priming. This priming effect appears to be independent of subjects' explicit memory for the objects, which we believe is handled by an episodic memory system.

We should stress that we have opted for a multiplesystems interpretation of our data because of the existence of converging evidence from independent lines of investigation: the neuropsychological research described above has provided evidence concerning the nature of the structural description system, and our studies indicate that priming of both novel and familiar objects is a presemantic phenomenon that can be experimentally dissociated from explicit memory. Although we think that our position is complementary to, rather than in conflict with, the processing views of implicit memory advocated by such investigators as Roediger et al. (1989), Moscovitch, Winocur, and McLachlan (1986), Jacoby (1983), and Masson (1989), we wish to emphasize the usefulness of a systems approach in organizing and integrating diverse observations concerning the nature of implicit memory.

\section{REFERENCES}

Bentin, S., \& Moscovitch, M. (1988). The time course of repetition effects for words and unfamiliar faces. Journal of Experimental Psychology: General, 117, 148-160.

Butters, N., Heindel, W. C., Salmon, D. P. (1990). Dissociation of implicit memory in dementia: Neurological implications. Bulletin of the Psychonomic Society, 28, 000-000.

Gabrieli, J. D. E., Milberg, W., Keane, M. M., \& Corkin, S. (in press). Intact priming of patterns despite impaired memory. Neuropsychologia.

JACOBY, L. L. (1983). Remembering the data: Analyzing interactive processes in reading. Journal of Verbal Learning \& Verbal Behavior, 22, 485-508.

Kroll, J. F., \& PotTer, M. C. (1984). Recognizing words, pictures, and concepts: A comparison of lexical, object, and reality decisions. Journal of Verbal Learning \& Verbal Behavior, 23, 39-66.

Masson, M. (1989). Fluent reprocessing as an implicit expression of memory for experience. In S. Lewandowsky, J. Dunn, \& K. Kirsner (Eds.), Implicit memory: Theoretical issues (pp. 123-138). Hillsdale, NJ: Erlbaum.

Moscovitch, M., Winocur, G., \& Mclachlan, D. (1986). Memory as assessed by recognition and reading time in normal and memoryimpaired people with Alzheimer's and other neurological disorders. Journal of Experimental Psychology: General, 115, 331-347.

Musen, G., \& Treisman, A. (1990). Implicit and explicit memory for visual patterns. Journal of Experimental Psychology: Learning, Memory, \& Cognition, 16, 127-137.

Peterson, S. E., Fox, P. T., Posner, M. I., \& Raichle, M. E. (1988) Position emission tomographic studies of the cortical anatomy of singleword processing. Nature, 331, 585-589.

RidDoch, M. J., \& HuMPHREYs, G. W. (1987). Visual object processing in optic aphasia: A case of semantic access agnosia. Cognitive Neuropsychology, 4, 131-186.

Roediger, H. L., III, Weldon, S., \& Challis, B. (1989). Explaining dissociations between implicit and explicit measures of retention: $\mathbf{A}$ processing account. In H. L. Roediger III \& F. I. M. Craik (Eds.), Varieties of memory and consciousness: Essays in honor of Endel Tulving (pp. 3-41). Hillsdale, NJ: Erlbaum.

SCHACTER, D. L. (in press). Perceptual representation systems and implicit memory: Toward a resolution of the multiple memory systems debate. In A. Diamond (Ed.), Development and neural bases of higher cognitive function. New York: Annals of the New York Academy of Sciences.

Schacter, D. L., CoOper, L. A., \& Delaney, S. M. (1990). Implicit memory for unfamiliar objects depends on access to structural descriptions. Journal of Experimental Psychology: General, 119, 5-21.

Schacter, D. L., Cooper, L. A., Delaney, S. M., Peterson, M. A., \& Tharan, M. (1990). Implicit memory for possible and impossible objects: Constraints on the construction of structural descriptions. Submitted for publication.

Schacter, D. L., Delaney, S. M., \& Merikle, E. P. (in press). Priming of nonverbal information and the nature of implicit memory. In G. H. Bower (Ed.), The psychology of learning and motivation (Vol. 26). New York: Academic Press.

SCHACTER, D. L., \& MerIKLE, E. P. (1990). [Priming of familiar visual objects]. Unpublished data.

Schacter, D. L., Rapscak, S., Rubens, A., Tharan, M., \&aGUNA, J. (1990). Priming effects in a letter-by-letter reader depend upon access to the word form system. Manuscript submitted for publication.

Schwartz, M. F., Marin, O. S. M., \& Saffran, E. M. (1979). Dissociations of language function in dementia: A case study. Brain \& Language, 7, 277-306.

SNODGRASS, J. G. (1989). Sources of learning in the picture fragment completion test. In S. Lewandowsky, J. Dunn, \& K. Kirsner (Eds.), Implicit memory: Theoretical issues (pp. 259-284). Hillsdale, NJ: Erlbaum.

Tulving, E., \& SCHACTER, D. L. (1990). Priming and human memory systems. Science, 247, 301-306.

WARRINGTON, E. K. (1975). The selective impairment of semantic memory. Quarterly Journal of Experimental Psychology, 27, 635-657.

WARRINGTON, E. K. (1982). Neuropsychological studies of object recognition. Philosophical Transactions of the Royal Society, London, Series $\mathrm{B}, 298,15-33$.

WARRINGTON, E. K., \& WeisKrantZ, L. (1968). New method of testing long-term retention with special reference to amnesic patients. Nature, 217, 972-974.

Weldon, M. S., \& Roediger, H. L., III. (1987). Altering retrieval demands reverses the picture superiority effect. Memory \& Cognition, 15, 269-280. 